\title{
Sonic hedgehog inversely regulates the expression of angiopoietin-1 and angiopoietin-2 in fibroblasts
}

\author{
SAE-WON LEE ${ }^{1}$, MICHAEL A. MOSKOWITZ ${ }^{1}$ and JOHN R. SIMS ${ }^{1,2}$ \\ ${ }^{1}$ Stroke and Neurovascular Regulation Laboratory, Department of Radiology, ${ }^{2}$ Department of Neurology, \\ Massachusetts General Hospital, Harvard Medical School, Charlestown, MA 02129, USA
}

Received October 17, 2006; Accepted November 28, 2006

\begin{abstract}
Nerves and blood vessels have similar branching patterns and use common morphogenic molecules during development. Recent studies show that sonic hedgehog (Shh), a traditional neurogenic morphogen, is required for embryonic arterial differentiation and can induce angiogenesis. We investigated whether Shh regulates the expression of angiogenic factors. Using NIH3T3 embryonic fibroblast cells, we demonstrated that Shh increased the mRNA levels of angiopoietin-1 (Ang-1), a secreted ligand that regulates endothelial interaction with mural cells (pericytes and smooth muscle cells) and promotes blood vessel maturation. In contrast, Shh decreased mRNA levels of angiopoietin-2 (Ang-2), a negative modulator of Ang-1. By contrast, Shh did not change the expression of vascular endothelial growth factor (VEGF) mRNA, a potent endothelial mitogen. The effect of Shh appeared to be cell-type specific as the addition of Shh to neural progenitor cells or neurons did not alter Ang-1, Ang-2 or VEGF mRNA levels. The addition of cyclopamine, an inhibitor of Shh signaling, to NIH3T3 cells, suppressed the regulation of Ang-1 and Ang-2 mRNA levels in the presence of Shh. Collectively, our results suggest that Shh may contribute to blood vessel growth, maturation and stabilization in a neurovascular network by reciprocally regulating the vascular morphogens Ang-1 and Ang-2 in a cell-typespecific manner.
\end{abstract}

\section{Introduction}

Sonic hedgehog (Shh) is a secreted protein that acts as a morphogen in various tissues and organs (1). Shh is important in the proliferation and maintenance of adult stem cells $(2,3)$. The secreted Shh binds to its receptor Patched (Ptch), thereby inactivating Ptch-mediated repression of

Correspondence to: Dr John R. Sims, Stroke and Neurovascular Regulation Laboratory, Departments of Radiology and Neurology, Massachusetts General Hospital, Harvard Medical School, Charlestown, MA 02129, USA

E-mail: jsims@partners.org

Key words: hedgehog protein, angiogenesis, angiopoietin, neurovascular unit
Smoothened (Smo), which leads to activation of the transcription factor Gli1 (1). Shh regulates proliferation of embryonic neural progenitor cells (4), and acts as an axonal chemoattractant for midline axon guidance (5).

Studies have shown that Shh is involved in angiogenesis. Mice overexpressing Shh show hypervascularization of the neuroectoderm (6) whereas, Shh knockout mice have abnormal cardiovascular development (7). Shh indirectly stimulates angiogenesis in ischemic skeletal and cardiac muscles of adult mice $(8,9)$, and inhibition of the Shh pathway reduces retinal angiogenesis (10). In addition, Shh-treated vessels have larger lumens and contain more smooth muscle cells in the vessel wall than vascular endothelial growth factor (VEGF)-induced vessels $(9,11)$. However, the mechanism by which Shh promotes angiogenesis and vascular maturation is not fully understood.

Ang-1, Ang-2 and VEGF are essential signaling molecules involved in blood vessel formation and stabilization (12-14). Currently, the evidence supports the hypothesis that vascular formation is maintained by a balance between Ang-1 and Ang-2 (12). VEGF initiates proliferation and migration of endothelial cells and can promote the formation of new vessels $(12,15)$. Ang-1, a strong blood-vessel-anti-permeability factor, binds to the endothelial Tie2 receptor tyrosine kinase. Ang-1 is required for the stabilization of endothelial contacts with surrounding mural cells to form mature vessels $(13,14)$. Ang-1 upregulates tight junction proteins in endothelial cells, decreases brain microvessel permeability, and stimulates the formation of the blood-brain barrier (16). Moreover, Ang-1 suppresses VEGF-induced vascular permeability in the skin and inhibits the development of diabetic retinopathy $(17,18)$. Like Ang-1, Ang-2 also binds to the Tie2 receptor. However, Ang-2 has dual effects depending on VEGF levels. In the absence of VEGF, Ang-2 acts as an antagonist of Ang-1, inducing separation of the endothelial cells from mural cells and possibly inducing apoptosis, which leads to vessel regression. In the presence of VEGF, Ang-2 stimulates new vessel formation $(15,19)$.

Here, we demonstrated that a single signaling molecule, Shh, inversely regulates Ang-1 and Ang-2. We found that exogenous Shh protein increases the expression of Ang-1, but decreases Ang-2. In particular, the pattern of Shhmediated Ang-1/Ang-2 gene expression was clearly reversed by the Shh signaling pathway inhibitor, cyclopamine. These results indicate that Shh may play a regulatory role in the 
balance of Ang-1 and Ang-2, suggesting that Shh may be useful for therapeutic applications that require mature new vessel formation.

\section{Materials and methods}

Animals. Specific pathogen-free pregnant CD1 mice (embryonic day 14-16) were supplied from Charles River (Wilmington, MA) for isolation of neural progenitors and neurons. The Subcommittee on Research and Animal Care approved all animal use.

Preparation of neural progenitors and neurons. Fresh neural progenitor cells were isolated from the cortices of fetuses at embryonic day 14-16. Tissue was minced and incubated in a phosphate-buffered saline (PBS) solution containing $0.25 \%$ trypsin, $25 \mu \mathrm{g} / \mathrm{ml} \mathrm{DNase} \mathrm{I} \mathrm{at} 37^{\circ} \mathrm{C}$ for $20 \mathrm{~min}$. Subsequently, DMEM (Gibco Invitrogen) containing $10 \%$ fetal bovine serum (FBS) (Gibco Invitrogen) was added and then passed through a cell strainer (70 $\mu \mathrm{m}$ nylon filter; BD Falcon). The cells were centrifuged at $800 \mathrm{rcf}$ for $5 \mathrm{~min}$ and then the supernatant was removed. Cells were re-suspended in DMEM/F12 media (Gibco Invitrogen) supplemented with N2, 0.6\% glucose, HEPES $(50 \mathrm{mmol} / \mathrm{l})$, fibroblast growth factor-2 $(20 \mathrm{ng} / \mathrm{ml})$, epidermal growth factor $(20 \mathrm{ng} / \mathrm{ml})$, heparin $(5 \mu \mathrm{g} / \mathrm{ml}), 1 \%$ FBS and penicillin/streptomycin/amphotericin B (1:100 dilution, Gibco Invitrogen). The cells were plated onto polyD-lysine and laminin (PDL/L)-coated 24-well plates (Biocoat, BD Biosciences) at $2 \times 10^{5}$ cells/well. After $24 \mathrm{~h}$, $1 \%$ FBS was removed from the medium. Thereafter, halfmedia change was performed every 3 days. For neuron cultures, cells were purified as above. Cells were plated onto PDL/L-coated 24-well plates (Biocoat) at $3 \times 10^{5}$ cells/well and cultured with defined media, neurobasal medium (Gibco Invitrogen) containing B27, glutamine (2 mM) and $1 \%$ penicillin/streptomycin. On days $1-3$, glutamate $(25 \mu \mathrm{g} / \mathrm{ml})$ and $B$-mercaptoethanol $(10 \mu \mathrm{M})$ were added. On day 3, Ara-C $(10 \mu \mathrm{M})$ was added for $24 \mathrm{~h}$. Subsequent media changes consisted of the defined neurobasal media. Half-media change was performed every 3 days.

Cell line and reagents. NIH3T3, mouse embryonic fibroblast cells, were purchased (ATCC \#CRL-1658, American Type Culture Collection) and cultured in DMEM containing $10 \%$ FBS (Gibco Invitrogen) and 1\% penicillin/streptomycin. During murine recombinant Shh (mrShh) treatment, cells were washed and cultured in defined media consisting of $\mathrm{DMEM} \pm \mathrm{mrShh}$. mrShh was purchased from Stem Cell Technologies and cyclopamine from Toronto Research Chemicals.

Real-time PCR and end-point PCR. Total RNA from 24-well cell culture experiments was prepared using QIAshredder and RNeasy mini kit (Qiagen Inc.) according to the manufacturer's instructions. Identical amounts of RNA were converted into cDNA according to the SuperScript III FirstStrand Synthesis system for RT-PCR (Invitrogen), using random hexamer primers. Mouse Gli1, VEGF1 $\alpha$, Ang-1 and Ang-2 transcripts were analyzed with an ABI TaqMan system using TaqMan FAM labeled probes (Applied
Biosystems). Real-time reactions were carried out in 96-well plates in triplicate with a $25-\mu 1$ final volume. Real-time samples were run on an ABI PRISM-7000 sequence detection system (Applied Biosystems) and end-point PCR samples were run on a PTC-200 system (MJ Research) using the following conditions: $50^{\circ} \mathrm{C}$ for $2 \mathrm{~min}, 95^{\circ} \mathrm{C}$ for $10 \mathrm{~min}$, and 40 cycles of $95^{\circ} \mathrm{C}$ for $15 \mathrm{sec}$ and $60^{\circ} \mathrm{C}$ for $1 \mathrm{~min}$. Data were analyzed using Q-gene (20). Gene expression was normalized to the expression of endogenous control $18 \mathrm{~S}$ rRNA (Applied Biosystems).

Data analysis. For time-series studies, gene expression following mrShh treatment was normalized to its untreated control and harvested at the same time for each time point. For dose-response studies, gene expression in cells treated with mrShh was normalized to untreated cells. The mean level of gene expression was analyzed by analysis of variance. If significance was present then individual comparisons were performed by Bonnferoni correction for multiple comparisons. Significance was considered at $\mathrm{p}<0.05$.

\section{Results}

Regulation of Ang-1, Ang-2 and VEGF expression by mrShh in fibroblasts. We first tested the possibility that Shh might regulate the expression of angiogenic genes in fibroblasts which are an important source of many angiogenic factors $(13,21)$. To evaluate whether mrShh activated the Shh signaling pathway in NIH3T3 embryonic fibroblasts, we treated cells with 0-100 nM mrShh for $16 \mathrm{~h}$ (Fig. 1). Gli1 mRNA significantly increased at a $5-\mathrm{nM}$ mrShh treatment $(\mathrm{p}<0.01)$, and showed a robust dose-dependent upregulation $(\mathrm{p}<0.001)$ (Fig. 1A). This Gli1 increase indicated that NIH3T3 cells strongly responded to mrShh. Ang-1 mRNA showed a similar pattern as Gli1, although less robust, and was dose-dependently upregulated by mrShh from 5-100 nM $(\mathrm{p}<0.01$ and $\mathrm{p}<0.001)$ (Fig. 1B). To note, Ang-2 mRNA was decreased by mrShh (Fig. 1C), but there was no significant change in VEGF mRNA level at this dose range (Fig. 1D).

We next investigated temporal expression in response to mrShh treatment. NIH3T3 cells, grown in media with serum, were switched to defined media plus mrShh $(50 \mathrm{nM})$. Because serum deprivation alone is known to upregulate VEGF and Ang-2 (22-24), each time point after mrShh addition was normalized to its own time control (Fig. 2). Treatment increased Gli1 mRNA expression compared to the control at all time points beginning $4 \mathrm{~h}$ after treatment $(\mathrm{p} \leq 0.001)$ (Fig. 2A). Ang-1 mRNA levels did not increase above control levels until $16 \mathrm{~h}$ and remained elevated at $24 \mathrm{~h}(\mathrm{p}<0.05)$ (Fig. 2B). Conversely, Ang-2 mRNA was significantly downregulated by mrShh at 4,8 and $16 \mathrm{~h}$ compared to control time points and returned to baseline at $24 \mathrm{~h}(\mathrm{p}<0.05$ at $8 \mathrm{~h}, 16 \mathrm{~h}$; p=0.1 at $4 \mathrm{~h}$ ) (Fig. 2C). At $16 \mathrm{~h}$, mrShh affected both Ang-1 and Ang-2 mRNA levels; Ang-1 increased and Ang-2 decreased in fibroblasts (Fig. 2B and C). At no time point was VEGF mRNA significantly altered by $\mathrm{mrShh}$ compared to control (Fig. 2D).

Shh is not expressed in NIH3T3 but expressed in neural progenitors and neurons. Because mrShh significantly alters 
A

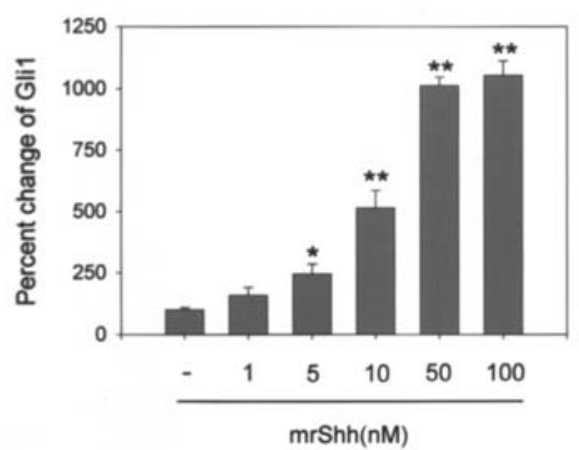

C

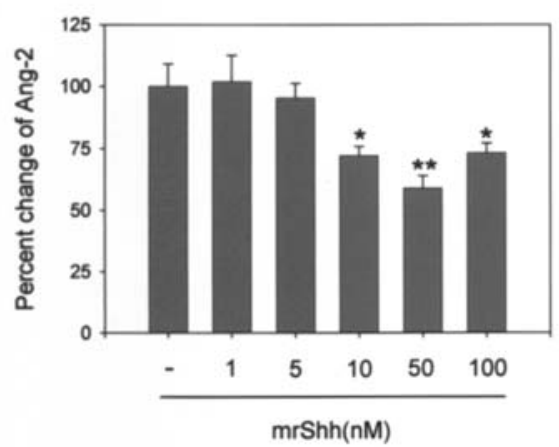

B

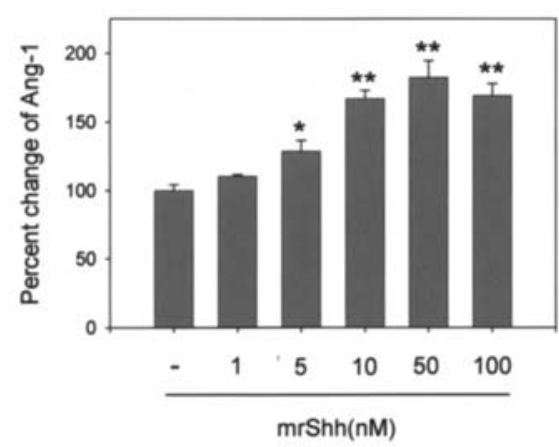

D

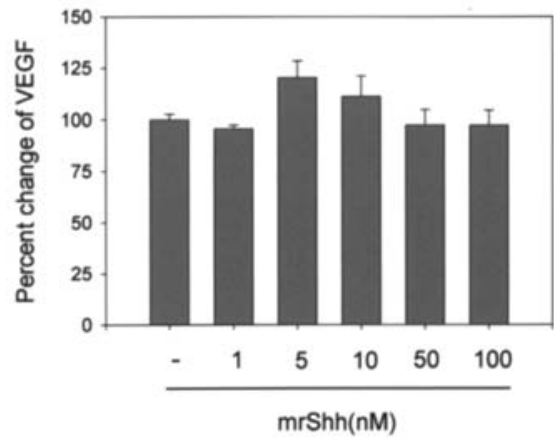

Figure 1. mrShh dose-dependently regulates Gli1, Ang-1 and Ang-2 gene expression in NIH3T3 cells. NIH3T3 cells were incubated with 0-100 nM mrShh for $16 \mathrm{~h}$ after which Gli1 (A), Ang-1 (B), Ang-2 (C) and VEGF (D) mRNA levels were detected by real-time PCR. mRNA levels were normalized to control $18 \mathrm{~S}$ rRNA. Data are expressed as the mean $\pm \mathrm{SE}$ from two independent experiments performed in triplicate for each condition. (A and $\mathrm{B}$, ${ }^{*} \mathrm{p}<0.01$ and ${ }^{* *} \mathrm{p}<0.001$ compared to control; $\mathrm{C},{ }^{*} \mathrm{p}<0.05$ and ${ }^{* *} \mathrm{p}<0.005$ compared to control).

$\mathbf{A}$

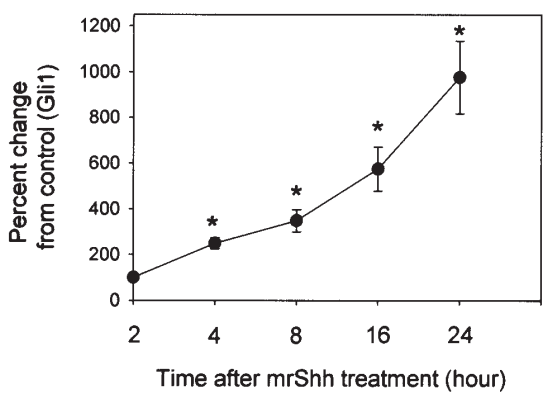

$\mathbf{C}$

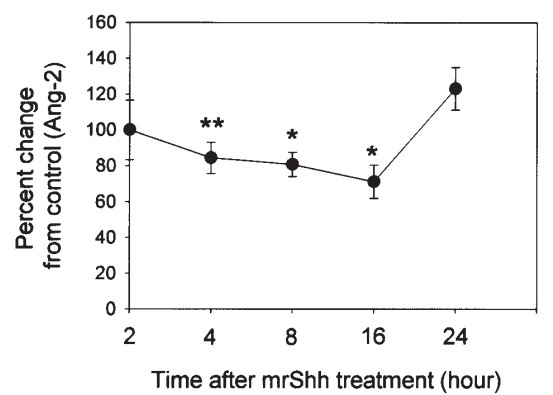

B

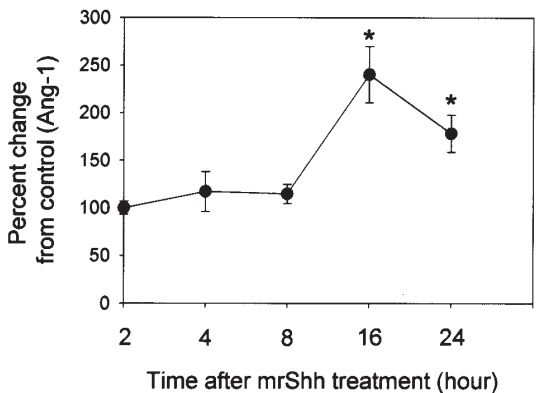

D

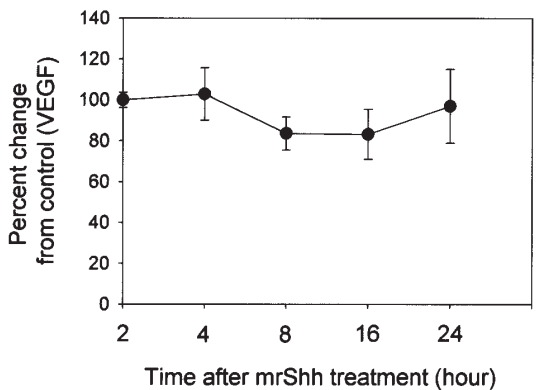

Figure 2. Time-course of Gli1, Ang-1, Ang-2 and VEGF expression after adding mrShh to NIH3T3 cells. mRNA expression was analyzed by real-time PCR after NIH3T3 cells were treated with $50 \mathrm{nM}$ mrShh for 2-24 h. Gene expression for Gli1 (A), Ang-1 (B), Ang-2 (C) and VEGF (D) was normalized to control $18 \mathrm{~S}$ rRNA. Gene expression of cells treated with $\mathrm{mrShh}$ was normalized to its untreated control, harvested at the same time for each time point (mean $\pm \mathrm{SE}$, for four independent experiments). (A, ${ }^{*} \mathrm{p} \leq 0.001$ compared to each control; B and $\mathrm{C},{ }^{*} \mathrm{p}<0.05$ compared to each control; $\mathrm{C},{ }^{* *} \mathrm{p}=0.1$ compared to control). 


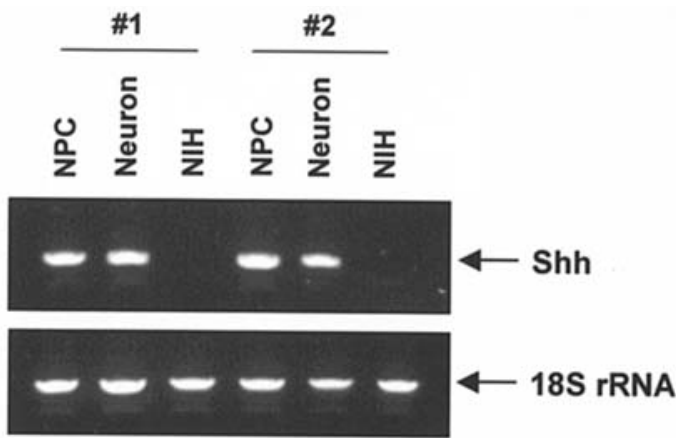

Figure 3. Shh expression in three types of cells. End-point PCR analysis was performed for mRNA expression of Shh, and the PCR fragments were separated by agarose gel electrophoresis. The same RNA samples were analyzed using primers of $18 \mathrm{~S}$ rRNA to confirm that the equal amounts of RNA were loaded. PCR products from two independent experiments were used for agarose gel electrophoresis. NPC, neural progenitor cells; NIH, NIH3T3 fibroblasts.

NIH3T3 cell expression of angiogenic factors Ang-1 and Ang-2, we analyzed NIH3T3 cells for Shh expression. Our results demonstrated that NIH3T3 fibroblasts do not synthesize Shh (Fig. 3). This result was confirmed by a more sensitive assay, performed with TaqMan probes and realtime PCR, with a detection limit of one mRNA copy of Shh for 10 billion copies of endogenous control 18S rRNA. Furthermore, Shh expression in fibroblasts was not induced after exposure to hypoxia, a strong angiogenic stimulus
$(12,25)$ (data not shown), whereas, Shh mRNA was detected in both cultured neural progenitors and neurons under both normal (Fig. 3) and hypoxic conditions (data not shown).

Shh does not regulate Ang-1, Ang-2 or VEGF expression in neural progenitors and neurons. Because neural progenitors and neurons are a source of Shh, we next examined whether Ang-1, Ang-2 and VEGF gene expression was modulated by adding mrShh to these cells. As shown in Fig. 4A, Gli1 expression was strongly increased in neural progenitors, and modestly in neurons, in a dose-dependent manner, demonstrating Shh responsiveness. Unlike NIH3T3 fibroblasts, Ang-1 or Ang-2 was not changed (Fig. 4B and C). Also, VEGF mRNA levels were not changed by mrShh (Fig. 4D). Adding $300 \mathrm{nM}$ of mrShh also did not change Ang-1, Ang-2 or VEGF expression, and no further increase in neuronal Gli1 mRNA expression was seen at this dose (data not shown).

Cyclopamine alters the effect of mrShh on Ang-1 and Ang-2 expression in NIH3T3 cells. Cyclopamine, a specific inhibitor of the Shh signaling pathway blocks downstream from the Shh receptor Ptch, and directly inhibits Smo activity (26). As shown in Fig. 5A, Gli1 stimulation was clearly blocked by cyclopamine. Ang-1 upregulation by mrShh was attenuated at $20 \mu \mathrm{M}$ only, whereas suppression of Ang-2 by mrShh was completely reversed by cyclopamine at 10 and $20 \mu \mathrm{M}$ (Fig. 5B and C). We calculated the Ang-1 to Ang-2 ratio (Fig. 5D), because the balance between these two factors may be important in vessel maturation and stability (12). In vivo,
A

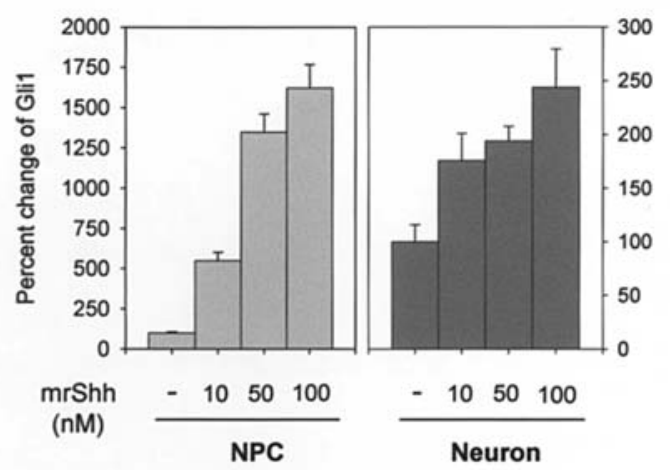

C

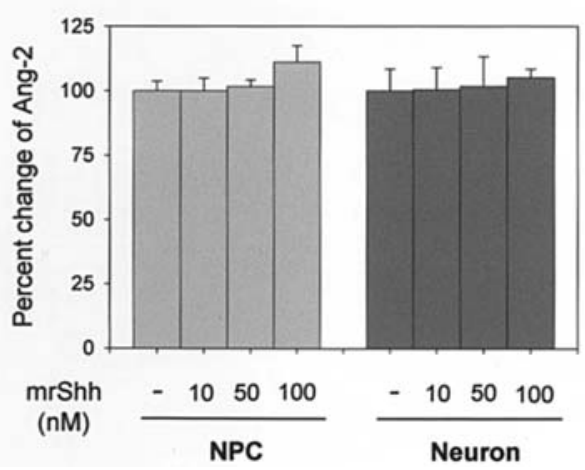

B

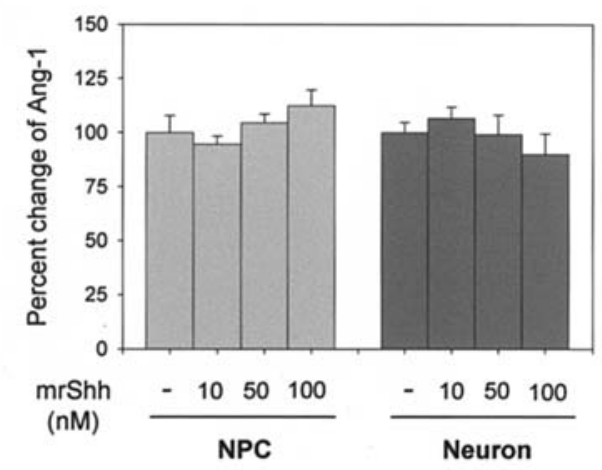

D

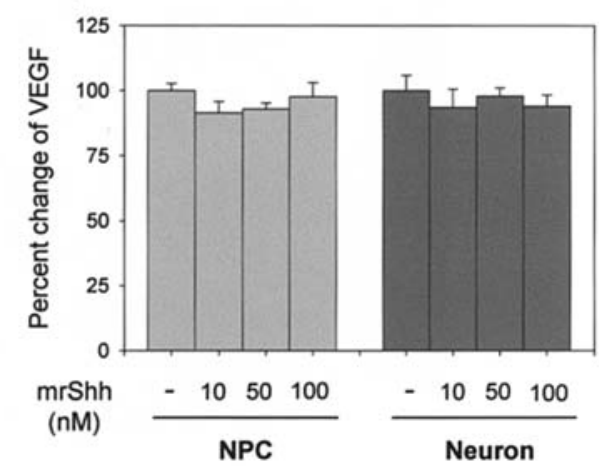

Figure 4. Regulation of Gli1, Ang-1, Ang-2 and VEGF mRNA expression in neural progenitors and neurons. Real-time PCR analysis showed mRNA levels of Gli1 (A), Ang-1 (B), Ang-2 (C) and VEGF (D) in neural progenitors and neurons treated with 0-100 nM mrShh for 16 h. mRNA levels were normalized to $18 \mathrm{~S}$ rRNA. Data were expressed as mean \pm SE from two independent experiments performed in triplicate for each condition. 
A

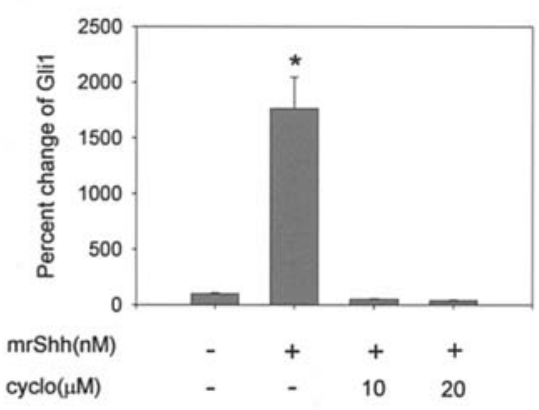

C

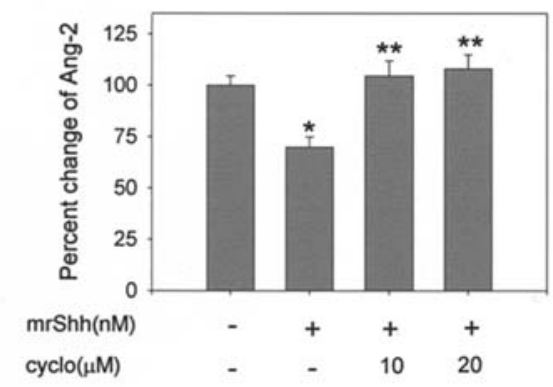

B

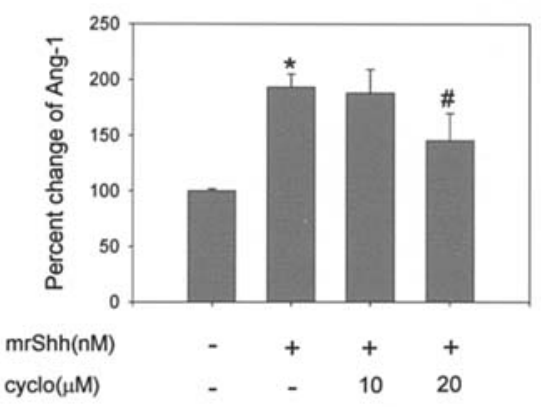

D

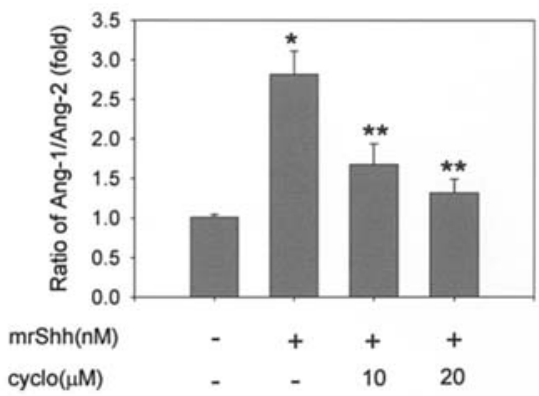

Figure 5. Cyclopamine blocks the regulatory activity of mrShh in Ang-1 and Ang-2 gene expression. Real-time PCR analysis was performed to investigate the effect of mrShh and cyclopamine for $16 \mathrm{~h}$ of incubation in NIH3T3 fibroblasts. Gene expression of Gli1 (A), Ang-1 (B) and Ang-2 (C) were expressed as mean \pm SE from four independent experiments. (D) The Ang-1 to Ang-2 ratio was calculated and shown as mean \pm SE. For A-D, ${ }^{*} \mathrm{p}<0.001$ compared to control; $\mathrm{C}$ and $\mathrm{D},{ }^{* *} \mathrm{p}<0.05$ compared to $\mathrm{mrShh}$ alone treated cells; $\mathrm{B},{ }^{*} \mathrm{p}=0.06$ compared to mrShh alone treated cells. Three independent experiments were performed. Cyclo; cyclopamine.

this ratio of angiopoietin factors has been demonstrated to fluctuate during angiogenesis or blood vessel regression $(27,28)$. The change in the Ang-1/Ang-2 ratio illustrates the effect of mrShh more clearly. mrShh treatment increased the ratio of Ang-1/Ang-2 by 2 .8-fold compared with control. However, cyclopamine significantly decreased this ratio compared with cells treated only with mrShh. These results indicated that Shh inversely regulates the expression of angiopoietins in NIH3T3 cells.

\section{Discussion}

Neural and vascular networks share common morphogenetic signals and mechanisms during development (29). Arteries align themselves with peripheral nerves and follow their branching patterns (30). Sensory nerves may serve as a template to determine the pattern of arterial differentiation and blood vessel branching by locally secreting VEGF. In addition to their traditional role as axonal guidance cues during development; netrins, semaphorins, ephrins and Slits may also guide blood vessels (29).

In our study, mrShh upregulated the expression of Ang-1, but reduced Ang-2 in fibroblasts (Figs. 1, 2 and 5). This coordinated change in expression of Ang-1 and Ang-2 suggests that Shh facilitates smooth muscle cell recruitment and endothelial-smooth muscle cell interaction in new vessels, thereby promoting a mature impermeable neovascularization. The temporal course of expression matches well with other reports of gene regulation by different modulatory factors of angiopoietins, such as TNF $\alpha$, hypoxia, and VEGF (31-34).
Notably, we show that Ang-2 downregulation occurs as early as $4 \mathrm{~h}$ after treatment and returns to baseline by $24 \mathrm{~h}$. This early response pattern followed by a return to baseline has been reported with Ang-2 upregulation (31-34). In contrast, Ang-1 has a delayed upregulation and peaks at $16 \mathrm{~h}$ and does not return to baseline, consistent with other reports $(31,35)$. This differential temporal expression supports the working hypothesis that Ang-2 is the rapid response element of vascular homeostasis. Thus, rapid and temporary changes in Ang-2 modulate the more constant and constitutive expression of Ang-1 stimulation of the Tie2 receptor, thereby producing blood vessel regression, sprouting or maturation $(36,37)$.

Several reports suggest that $\mathrm{Shh}$, a regulator of neurogenesis, also impacts angiogenesis (8-11,38). Shh and VEGF promote arterial endothelial differentiation in zebrafish embryo (38). Shh treatment restores vasa nervora of peripheral nerves, and improves conduction velocities in a rodent model of diabetic peripheral neuropathy (11). New capillaries forming from pre-existing blood vessels mature by recruiting perivascular fibroblasts and smooth muscle cells (13). Ang-1 and Ang-2 were originally discovered as an endothelialspecific growth factor $(13,14)$. Ang-1 recruits mural cells into the walls of developing vessels where the cells differentiate into pericytes and smooth muscle cells. Thus, Ang-1 tightens vessels by affecting junctional molecules and by stimulating the interaction between endothelial and mural cells $(16,18)$. Thurston et al suggested that combining Ang-1 with VEGF could promote angiogenesis without enhancing permeability (39). Ang-2 reportedly weakens endothelial-mural cell interactions and degrades the extracellular matrix, thereby 
antagonizing Ang-1 (40). When insufficient angiogenic signals are present, Ang-2 leads to endothelial death and vessel regression $(12,14,19)$.

Fibroblasts are an integral component of all tissues; they can differentiate into pericytes or smooth muscle cells and can regulate endothelial cell migration, viability, and capillary-like network formation $(41,42)$. Fibroblasts contribute to tissue architecture by producing matrix proteins (13) and are an important source of many growth factors for endothelial cells such as VEGF, fibroblast growth factor, and platelet-derived growth factor $(13,21)$. In our study, mrShh did not regulate neural progenitor or neuron mRNA levels of Ang-1 or Ang-2 (Fig. 4), in contrast to NIH3T3 embryonic fibroblasts (Figs. 1,2 and 5). Our data suggest that fibroblasts, not neural progenitors or neurons, respond to Shh and contribute to Ang-1 and Ang-2 expression. The source of Shh is possibly from neural progenitor cells or neurons, but not fibroblasts. Thus, Shh from neural cells may influence fibroblast expression of Ang-1/Ang-2 via a paracrine mechanism, which in turn would regulate endothelial cells via their specific receptors.

It is unclear how Shh may regulate both Ang-1 and Ang-2. Blocking Shh signaling through Smo via cyclopamine, suggests that Ang-2 regulation may be downstream of Gli1 activation. However, cyclopamine was unable to completely block Ang-1 upregulation at maximal Gli1 inhibition, suggesting an alternative regulating pathway other than Gli1.

The present study demonstrates that Shh regulates gene expression of angiogenic factors, by increasing Ang-1 and decreasing Ang-2. Shh may thus shift the balance of angiogenic factors towards a maturing vascular network. An improved understanding of the angiogenic mechanisms induced by Shh could provide useful therapeutic targets for the treatment of vascular diseases.

\section{Acknowledgements}

This study was supported by the American Heart Association, National Scientist Development Grant no. 0535138N (J.R. Sims), and the Korea Research Foundation Grant no. M012004-000-10335-0 (S-W. Lee), NIH Interdepartmental Stroke Program Project no. 5 P50 NS10828, and NIH Nucleic Acid Quantitation Core Grant no. NS045776.

\section{References}

1. Cohen MM Jr: The hedgehog signaling network. Am J Med Genet A 123: 5-28, 2003.

2. Machold R, Hayashi S, Rutlin M, et al: Sonic hedgehog is required for progenitor cell maintenance in telencephalic stem cell niches. Neuron 39: 937-950, 2003.

3. Palma V, Lim DA, Dahmane N, et al: Sonic hedgehog controls stem cell behavior in the postnatal and adult brain. Development 132: 335-344, 2005.

4. Zhu G, Mehler MF, Zhao J, Yung SY and Kessler JA: Sonic hedgehog and BMP2 exert opposing actions on proliferation and differentiation of embryonic neural progenitor cells. Dev Biol 215: 118-129, 1999.

5. Charron F, Stein E, Jeong J, McMahon AP and Tessier-Lavigne M: The morphogen sonic hedgehog is an axonal chemoattractant that collaborates with netrin-1 in midline axon guidance. Cell 113: 11-23, 2003.

6. Rowitch DH, St.-Jacques B, Lee SM, Flax JD, Snyder EY and McMahon AP: Sonic hedgehog regulates proliferation and inhibits differentiation of CNS precursor cells. J Neurosci 19: 8954-8965, 1999.
7. Chiang C, Litingtung Y, Lee E, et al: Cyclopia and defective axial patterning in mice lacking Sonic hedgehog gene function. Nature 383: 407-413, 1996.

8. Pola R, Ling LE, Aprahamian TR, et al: Postnatal recapitulation of embryonic hedgehog pathway in response to skeletal muscle ischemia. Circulation 108: 479-485, 2003.

9. Pola R, Ling LE, Silver M, et al: The morphogen Sonic hedgehog is an indirect angiogenic agent upregulating two families of angiogenic growth factors. Nat Med 7: 706-711, 2001.

10. Surace EM, Balaggan KS, Tessitore A, et al: Inhibition of ocular neovascularization by hedgehog blockade. Mol Ther 13: 573-579, 2006.

11. Kusano KF, Allendoerfer KL, Munger W, et al: Sonic hedgehog induces arteriogenesis in diabetic vasa nervorum and restores function in diabetic neuropathy. Arterioscler Thromb Vasc Biol 24: 2102-2107, 2004.

12. Carmeliet P: Angiogenesis in health and disease. Nat Med 9: 653-660, 2003.

13. Jain RK: Molecular regulation of vessel maturation. Nat Med 9: 685-693, 2003.

14. Yancopoulos GD, Davis S, Gale NW, Rudge JS, Wiegand SJ and Holash J: Vascular-specific growth factors and blood vessel formation. Nature 407: 242-248, 2000.

15. Holash J, Wiegand SJ and Yancopoulos GD: New model of tumor angiogenesis: dynamic balance between vessel regression and growth mediated by angiopoietins and VEGF. Oncogene 18: 5356-5362, 1999.

16. Lee SW, Kim WJ, Choi YK, et al: SSeCKS regulates angiogenesis and tight junction formation in blood-brain barrier. Nat Med 9: 900-906, 2003.

17. Joussen AM, Poulaki V, Tsujikawa A, et al: Suppression of diabetic retinopathy with angiopoietin-1. Am J Pathol 160: 1683-1693, 2002.

18. Thurston G, Rudge JS, Ioffe E, et al: Angiopoietin-1 protects the adult vasculature against plasma leakage. Nat Med 6: 460-463, 2000.

19. Oshima Y, Oshima S, Nambu H, et al: Different effects of angiopoietin-2 in different vascular beds: new vessels are most sensitive. FASEB J 19: 963-965, 2005.

20. Muller PY, Janovjak H, Miserez AR and Dobbie Z: Processing of gene expression data generated by quantitative real-time RT-PCR. Biotechniques 32: 1372-1379, 2002.

21. Ruiter D, Bogenrieder T, Elder D and Herlyn M: Melanomastroma interactions: structural and functional aspects. Lancet Oncol 3: 35-43, 2002.

22. Gnarra JR, Zhou S, Merrill MJ, et al: Post-transcriptional regulation of vascular endothelial growth factor mRNA by the product of the VHL tumor suppressor gene. Proc Natl Acad Sci USA 93: 10589-10594, 1996.

23. Phelps ED, Updike DL, Bullen EC, Grammas P and Howard EW: Transcriptional and posttranscriptional regulation of angiopoietin-2 expression mediated by IGF and PDGF in vascular smooth muscle cells. Am J Physiol Cell Physiol 290: C352-C361, 2006.

24. Yu Y, Varughese J, Brown LF, Mulliken JB and Bischoff J: Increased Tie2 expression, enhanced response to angiopoietin-1, and dysregulated angiopoietin-2 expression in hemangiomaderived endothelial cells. Am J Pathol 159: 2271-2280, 2001.

25. Pugh CW and Ratcliffe PJ: Regulation of angiogenesis by hypoxia: role of the HIF system. Nat Med 9: 677-684, 2003.

26. Taipale J, Chen JK, Cooper MK, et al: Effects of oncogenic mutations in Smoothened and Patched can be reversed by cyclopamine. Nature 406: 1005-1009, 2000.

27. Hirchenhain J, Huse I, Hess A, Bielfeld P, De Bruyne F and Krussel JS: Differential expression of angiopoietins 1 and 2 and their receptor Tie-2 in human endometrium. Mol Hum Reprod 9: 663-669, 2003.

28. Sandhu R, Teichert-Kuliszewska K, Nag S, et al: Reciprocal regulation of angiopoietin- 1 and angiopoietin- 2 following myocardial infarction in the rat. Cardiovasc Res 64: 115-124, 2004.

29. Carmeliet $P$ and Tessier-Lavigne $\mathrm{M}$ : Common mechanisms of nerve and blood vessel wiring. Nature 436: 193-200, 2005.

30. Mukouyama YS, Shin D, Britsch S, Taniguchi M and Anderson DJ: Sensory nerves determine the pattern of arterial differentiation and blood vessel branching in the skin. Cell 109: 693-705, 2002.

31. Hangai M, He S, Hoffmann S, Lim JI, Ryan SJ and Hinton DR: Sequential induction of angiogenic growth factors by TNF-alpha in choroidal endothelial cells. J Neuroimmunol 171: 45-56, 2006. 
32. Kim I, Kim JH, Ryu YS, Liu M and Koh GY: Tumor necrosis factor-alpha upregulates angiopoietin-2 in human umbilical vein endothelial cells. Biochem Biophys Res Commun 269: 361-365, 2000.

33. Krikun G, Schatz F, Finlay T, et al: Expression of angiopoietin-2 by human endometrial endothelial cells: regulation by hypoxia and inflammation. Biochem Biophys Res Commun 275: 159-163, 2000.

34. Zhang L, Yang N, Park JW, et al: Tumor-derived vascular endothelial growth factor up-regulates angiopoietin-2 in host endothelium and destabilizes host vasculature, supporting angiogenesis in ovarian cancer. Cancer Res 63: 3403-3412, 2003.

35. Hangai M, Murata T, Miyawaki N, et al: Angiopoietin-1 upregulation by vascular endothelial growth factor in human retinal pigment epithelial cells. Invest Ophthalmol Vis Sci 42: 1617-1625, 2001.

36. Brindle NP, Saharinen P and Alitalo K: Signaling and functions of angiopoietin-1 in vascular protection. Circ Res 98: 1014-1023, 2006.
37. Hanahan D: Signaling vascular morphogenesis and maintenance. Science 277: 48-50, 1997.

38. Lawson ND, Vogel AM and Weinstein BM: Sonic hedgehog and vascular endothelial growth factor act upstream of the Notch pathway during arterial endothelial differentiation. Dev Cell 3: 127-136, 2002.

39. Thurston G, Suri C, Smith K, et al: Leakage-resistant blood vessels in mice transgenically overexpressing angiopoietin- 1 . Science 286: 2511-2514, 1999.

40. Gale NW, Thurston G, Hackett SF, et al: Angiopoietin-2 is required for postnatal angiogenesis and lymphatic patterning, and only the latter role is rescued by angiopoietin-1. Dev Cell 3: 411-423, 2002.

41. Kunz-Schughart LA, Schroeder JA, Wondrak M, et al: Potential of fibroblasts to regulate the formation of three-dimensional vessel-like structures from endothelial cells in vitro. Am J Physiol Cell Physiol 290: C1385-C1398, 2006.

42. Velazquez OC, Snyder R, Liu ZJ, Fairman RM and Herlyn M: Fibroblast-dependent differentiation of human microvascular endothelial cells into capillary-like 3-dimensional networks. FASEB J 16: 1316-1318, 2002. 